University of Nebraska - Lincoln

DigitalCommons@University of Nebraska - Lincoln

Publications of the University of Nebraska

Public Policy Center

Public Policy Center, University of Nebraska

2013

\title{
Factor Structure and Construct Validity of the Psychopathic Personality Inventory in a Forensic Sample
}

Valerie M. Gonsalves

Sand Ridge Secure Treatment Center, Mauston,WI, valerie.gonsalves@wi.gov

Julia E. McLawsen

University of Washington/Special Commitment Center, juliamcc@uw.edu

Matthew T. Huss

Creighton University,mhuss@creighton.edu

Mario J. Scalora

University of Nebraska-Lincoln, mscalora1@unl.edu

Follow this and additional works at: https://digitalcommons.unl.edu/publicpolicypublications

Part of the Other Public Affairs, Public Policy and Public Administration Commons, Other Social and Behavioral Sciences Commons, Public Affairs Commons, Public Policy Commons, and the Social Policy Commons

Gonsalves, Valerie M.; McLawsen, Julia E.; Huss, Matthew T.; and Scalora, Mario J., "Factor Structure and Construct Validity of the Psychopathic Personality Inventory in a Forensic Sample" (2013). Publications of the University of Nebraska Public Policy Center. 191.

https://digitalcommons.unl.edu/publicpolicypublications/191

This Article is brought to you for free and open access by the Public Policy Center, University of Nebraska at DigitalCommons@University of Nebraska - Lincoln. It has been accepted for inclusion in Publications of the University of Nebraska Public Policy Center by an authorized administrator of DigitalCommons@University of Nebraska - Lincoln. 


\title{
Factor structure and construct validity of the psychopathic personality inventory in a forensic sample
}

\author{
Valerie M. Gonsalves, ${ }^{1}$ Julia E. McLawsen, ${ }^{2}$ \\ Matthew T. Huss, ${ }^{3}$ Mario J. Scalora ${ }^{4}$
}

\begin{abstract}
1 Sand Ridge Secure Treatment Center, Mauston, WI, USA
2 University of Washington/Special Commitment Center, McNeil Island, WA, USA

3 Creighton University, Omaha, NE, USA

4 University of Nebraska-Lincoln, Lincoln, NE, USA

Corresponding author - M. T. Huss, Creighton University, Hixson-Lied 307, Omaha, NE 68178, emailmhuss@creighton.edu
\end{abstract}

\begin{abstract}
A wealth of research has underscored the strong relationship between PCL-R scores and recidivism. However, mounting criticism cites the PCL-R's cumbersome administration procedures and failure to adequately measure core features associated with the construct of psychopathy (Skeem, Polaschek, Patrick, \& Lilienfeld, 2011). In light of these concerns, this study examined the PPI and the PPI-R, which were designed to measure core personality features associated with psychopathy (Lilienfeld \& Andrews, 1996; Lilienfeld \& Widows, 2005). Study one examined the PPI relative to the PCL-R and examined its factor structure. The instruments shared few significant correlations and neither the PCL-R nor the PPI significantly predicted recidivism. Study two examined the PPI-R relative to the PCL-R, the PPI, both history of violence and future criminal activity and measure of related constructs. The PPI-R was significantly correlated with measures of empathy and criminal thinking and the factors were related to a history of violence and predicted future violent criminal behavior.
\end{abstract}

Keywords: Recidivism, Psychopathy, Assessment, Empathy, Criminal thinking

Published in International Journal of Law and Psychiatry 36 (2013), pp 176-184.

doi:10.1016/j.ijlp.2013.01.010

Copyright (C) 2013 Elsevier Ltd. Used by permission.

Published 8 February 2013. 


\section{Introduction}

Psychopathy has been one of the most widely studied constructs in correctional and forensic populations because of its relationship with increased institutional violence, poor treatment response, and general and violent recidivism (Poythress, Edens, \& Lilienfeld, 1998; Salekin, Rogers, \& Sewell, 1996; Wallace, Schmitt, Vitale, \& Newman, 2000; Walters, 2003). The Psychopathy Checklist-Revised (PCL-R; Hare, 1991, 2003) is the most commonly used measure of psychopathy. Although the strength of this instrument is well-established, disadvantages such as length of time needed for administration, heavy reliance on file review, and a focus on antisocial and criminal behaviors rather than personality features detract from its overall utility (Edens, Poythress, \& Watkins, 2001). Further, there is mounting concern that the field equates psychopathy with the manner in which the PCL-R measures it, which may promote a deficient understanding of core attributes associated with the actual construct (Skeem \& Cooke, 2010; Skeem, Polaschek, Patrick, \& Lilienfeld, 2011). To address several of these concerns, Lilienfeld and Andrews (1996) developed the Psychopathic Personality Inventory (PPI) as an alternative assessment instrument, designed for use with non-forensic populations. The PPI is well-regarded for its ability to assess personality characteristics, as opposed to behaviors, associated with psychopathy (Lilienfeld \& Andrews). This instrument was developed using an exploratory approach to test construction, allowing the initial set of items to be construct driven and the final set of items to be both construct and data driven (Lilienfeld \& Andrews, 1996).

Despite a number of studies examining the instrument in noninstitutional samples, just a handful of studies have examined the ability of this instrument to generalize to correctional samples. For example, Poythress et al. (1998) found that in a sample of 50 offenders, there were significant correlations between the PPI total score and the PCL-R total score $(r=.54)$ as well between the PPI total score and the PCL-R's Factor $1(r$ $=.54)$ and Factor $2(r=.40)$. Poythress and colleagues also noted several significant correlations between scales of the PPI and the PCL-R total score. In addition, they found an $86 \%$ classification rate in the ability of the PPI to classify the sample as psychopathic and nonpsychopathic (i.e., individuals with PCL-R scores above and below 30, respectively). The authors concluded that because the PPI allows evaluators to circumvent 
some of the more cumbersome aspects of administering the PCL-R, the PPI may have increased utility with a correctional population.

Subsequent studies have supported Poythress et al.'s (1998) findings. Edens, Poythress, and Lilienfeld (1999) found a significant correlation $(\mathrm{r}=.23)$ between the PPI total score and incidents of verbal aggression among a sample of 50 incarcerated young adults. The authors also examined the PCL-R and found that each instrument predicted institutional aggression alone, but combining them did not improve predictive power. The authors concluded that these findings were consistent with other research illustrating a connection between psychopathy and institutional misconduct, noting that the use of the PPI yielded similar results to the use of the PCL-R.

Factor analytic studies have suggested that seven of the eight PPI scales map onto two distinct factors (Benning, Patrick, Hicks, Blonigen, \& Krueger, 2003). PPI-I, also known as the Fearlessness Dominance scale, is comprised of the Stress Immunity, Social Potency, and Fearlessness subscales, and is marked by characteristics similar to those attributed to Factor 1 of the PCL-R. Similarly, PPI-II, also known as the Impulsive Antisociality factor, is comprised of Impulsive Nonconformity, Blame Externalization, Machiavellian Egocentricity, and Carefree Nonplanfulness. This factor is marked by traits associated with Factor 2 of the PCL-R. The similar structures of the PPI and PCL-R could enable researchers to compare different measures of psychopathy, as well as measure psychopathy via more efficient self-report methods. However, there are exceptions to the overall structural correspondence between the two instruments. For example, the PPI'ss Coldheartedness scale does not load onto either factor, suggesting that the PPI might be more accurately characterized by a three-factor model. Further, since the PPI's factor structure has not been examined extensively in correctional populations, the possibility remains that its factor structure may differ in non-undergraduate student samples. To this effect, a study that examined the PPI's factor structure in a correctional population found poor fit using a confirmatory factor analysis for the two-factor model (Neumann, Malterer, \& Newman, 2008). Using an exploratory factor analysis, Neumann and colleagues observed different results from those reported by Benning et al. (2003). Specifically, just the Fearlessness scale loaded onto the first factor, while the second factor was comprised of the Stress Immunity and Social Potency scales and the third factor consisted of the Coldheartedness and the Carefree 
Nonplanfulness scales (Neumann et al., 2008). Neumann and colleagues also found that their factor solution accounted for a smaller proportion of variance compared to Benning et al. (2003). Neumann et al. (2008) concluded that their findings did not support a two-factor model in a correctional population.

Despite its growing popularity, plus a handful of validation efforts in non-undergraduate samples, limited studies have examined the PPI in forensic samples. Given that forensic samples present in mental health settings, these individuals may have unique presentations of traits of psychopathy, necessitating a separate examination. Notably, the PCL$\mathrm{R}$ manual distinguishes between normative data for correctional samples and forensic samples, suggesting that previous authors examining psychopathy have discovered differences in the presentation across samples.

One study examined the PPI in a sample of insanity acquittees (Kruh et al., 2005). Kruh and colleagues found moderate to strong correlations between the Psychopathy Checklist: Screening Version (PCL:SV; Hart, Cox, \& Hare, 1995) total score and factor scores and the PPI total score and subscale scores. Interestingly, the study did not find a unique relationship between Factor 1 scores, which are commonly understood to represent cognitive and interpersonal aspects of psychopathy, and PPI scores. This study also found a relationship between the PPI total score and past violent offenses that was similar to the relationship found using the PCL:SV ( $r=.31-.34)$. Finally, regression analyses postdicting violence demonstrated that although the PPI total score improved the model's postdictive validity over using just the PCL:SV Factor 1 score, the PPI total and Factor 2 scores accounted for similar amounts of variance. Though these findings represent important first steps towards understanding the PPI's utility within a forensic sample, the study was plagued by a number of methodological problems including small sample size $(n=50)$ and reliance on the PCL:SV, which is less robust than the PCL$\mathrm{R}$ (Kruh et al., 2005). In addition, the study did not examine the two factor model proposed by Benning et al. (2003).

A revised version of the PPI, the Psychopathic Personality Inventory - Revised (PPI-R; Lilienfeld \& Widows, 2005), was published and items were reworded to reduce the instrument's reading level, so that the instrument could be administered in a wider range of forensic and clinical settings. Norms are provided for both a community/college sample 
as well as an offender samples. However, the manual provides the results of an exploratory factor analysis conducted on the community/ college sample, but not on the offender sample. The authors proposed the following three factor model: Self-Centered Impulsivity, Fearless Dominance, and Coldheartedness.

Thus far, scant published research has examined the PPI-R. Ray, Poythress, Weir, and Rickelm (2009) examined primary (low anxiety) and secondary (high anxiety) psychopathy. The authors used the two factors of the PPI-R, fearless dominance and self-centered impulsivity, as proxy variables for primary and secondary psychopathy, to determine the relationship between type of psychopathy and a number of impulsivity measures. They hypothesized that there would be a significant positive correlation between self-centered impulsivity and three impulsivity-related traits: urgency, premeditation and perseverance. Further, the authors predicted a significant positive relationship between sensation seeking and fearless dominance. Using a sample of 92 offenders, the authors found that their hypotheses were largely supported; however, bivariate analyses revealed a small, but significant association between fearless dominance and premeditation. From these results, the authors concluded that accounting for impulsivity may help differentiate between primary and secondary psychopathy in ways that traditional personality and psychopathy measures do not.

Given the limited amount of research regarding the PPI and the PPI$\mathrm{R}$ within a forensic sample, the present study sought to compare these measures to the PCL-R. As such, two studies were conducted. Study one tested the utility of the PPI in a forensic sample, while study two did the same with the PPI-R. In study one, it was hypothesized that the PPI total score would be significantly, positively correlated with the PCL-R total score and the PCL-R Factor scores. Further, it was expected that the two-factor model of psychopathy would be replicated utilizing the PPI in a forensic sample. Finally it was hypothesized that individuals scoring high on measures of psychopathy would be more likely to recidivate than those scoring low. In study two, the PPI and the PPI-R were compared to the PCL-R. It was hypothesized that the PPI-R would be positively correlated with constructs associated with psychopathy: criminal thinking, empathic deficits, and sensation-seeking. It was further hypothesized that there would be a positive relationship between measures of psychopathy, violent history, and future violent behavior. 


\section{Study one: Method}

\subsection{Participants}

A total of 143 male participants were recruited from a state forensic hospital. Participants were admitted to the hospital for a variety of reasons, including evaluation of competency to stand trial (5.7\%), evaluation of criminal responsibility (2.5\%), sexually violent predator evaluations (4.1\%), treatment for restoration of competency to stand trial (9.8\%), commitment after being found not guilty by reason of insanity (4.1\%), civil commitment (41.0\%), and sex offender treatment (21.3\%). The remainder of the sample was admitted for a variety of other reasons. The sample was predominately single (51.7\%) and White (62.9\%), with an average age of 33.86 (SD = 12.59; see Table 1 for sample data by instrument.) Most participants had been admitted to an inpatient psychiatric facility on at least one prior occasion (86.6\%), and most participants had been incarcerated prior to their admission (79.8\%). Considering recidivism, $58.04 \%(n=83)$ of the participants had been released into the community prior to data collection. Of those 83 released participants, $36.11 \%(n=30)$ were charged with or convicted of a subsequent offense. Means and standard deviations of the entire sample on the instruments utilized in both study one and study two are summarized in Table 2.

Table 1 Sample demographic data for samples.

\begin{tabular}{|c|c|c|c|c|}
\hline \multicolumn{2}{|l|}{$P C L-R$} & \multicolumn{3}{|c|}{ PPI-R $\quad P P I \& P P I-R$} \\
\hline \multicolumn{5}{|l|}{ Ethnicity } \\
\hline European-American/white & $75.9 \%$ & $72.6 \%$ & $76.6 \%$ & $76.5 \%$ \\
\hline African-American/black & $13.8 \%$ & $16.9 \%$ & $14.3 \%$ & $13.7 \%$ \\
\hline American Indian/Alaskan Native & e $1.7 \%$ & $2.4 \%$ & $1.3 \%$ & $2.0 \%$ \\
\hline Latino/Hispanic & $6.3 \%$ & $6.5 \%$ & $6.5 \%$ & $5.9 \%$ \\
\hline Native Hawaiian/Pacific Islande & r $1.7 \%$ & $.8 \%$ & $1.3 \%$ & $2.0 \%$ \\
\hline \multicolumn{5}{|c|}{ Marital status } \\
\hline Single & $60.3 \%$ & $60.2 \%$ & $55.7 \%$ & $46.2 \%$ \\
\hline Married & $20.7 \%$ & $17.9 \%$ & $16.5 \%$ & $23.1 \%$ \\
\hline Divorced & $15.5 \%$ & $17.1 \%$ & $24.1 \%$ & $28.8 \%$ \\
\hline Widowed & $0 \%$ & $0 \%$ & $1.3 \%$ & $0 \%$ \\
\hline Separated & $3.4 \%$ & $4.9 \%$ & $1.3 \%$ & $1.9 \%$ \\
\hline Age (years) & $33.71(13.36)$ & $33.86(12.59)$ & 34.81 (12.59) & $37.58(12.24)$ \\
\hline Education (years) & $12.24(2.28)$ & $12.01(2.32)$ & $11.96(2.35)$ & $12.20(1.51)$ \\
\hline Recidivate (\% yes) & $13.6 \%$ & & $24.4 \%$ & $3.7 \%$ \\
\hline
\end{tabular}


Table 2 Descriptive data for the total sample with sample size for each instrument.

\begin{tabular}{|c|c|c|}
\hline & $M$ & $S D$ \\
\hline PCL-R total $(n=143)$ & 14.45 & 6.90 \\
\hline PCL-R Factor $1(n=143)$ & 6.84 & 3.62 \\
\hline PCL-R Factor $2(n=143)$ & 6.69 & 4.25 \\
\hline PPI total $(n=143)$ & 355.65 & 40.91 \\
\hline PPI-I (n = 143) & 129.90 & 20.36 \\
\hline PPI-II (n = 143) & 173.76 & 33.34 \\
\hline PPI-R total $(n=95)$ & 267.55 & 29.89 \\
\hline PPI-R SCI (n = 95) & 130.96 & 26.64 \\
\hline PPI-R FD (n = 95) & 104.24 & 17.97 \\
\hline PICTS total score $(n=95)$ & 102.59 & 27.55 \\
\hline PICTS Proactive $(\mathrm{n}=95)$ & 73.01 & 23.83 \\
\hline PICTS Reactive(n = 95) & 83.72 & 27.45 \\
\hline $\operatorname{ZTAS}(n=95)$ & 5.95 & 3.30 \\
\hline $\mathrm{ZES}(\mathrm{n}=95)$ & 4.33 & 1.96 \\
\hline ZDIS(n = 95) & 2.65 & 2.16 \\
\hline $\mathrm{ZBS}(\mathrm{n}=95)$ & 2.17 & 2.41 \\
\hline ZSSTOT $(\mathrm{n}=95)$ & 15.22 & 6.62 \\
\hline IRIPT(n = 95) & 20.68 & 20.59 \\
\hline $\operatorname{IRIEC}(\mathrm{n}=95)$ & 25.49 & 4.72 \\
\hline $\operatorname{IRIFS}(\mathrm{n}=95)$ & 19.60 & 6.35 \\
\hline $\operatorname{IRIPD}(\mathrm{n}=95)$ & 16.06 & 13.57 \\
\hline
\end{tabular}

\subsection{Measures}

Psychopathy Checklist - Revised (PCL-R; Hare, 1991, 2003). This instrument instructs clinicians to rate 20 items based upon on file review and a semi-structured interview. The clinician scores the items as either $0=$ item does not apply, $1=$ item applies to a limited extent, or $2=$ item definitely applies based on the lifetime prevalence of the characteristics or behaviors represented by each item. Individual item scores sum to an overall score. A score of 30 and above indicates a strong presence of psychopathic traits; however, some studies use a cut-off score of 25 (Huss \& Langhinrichsen-Rohling, 2006). Most research characterizes psychopathy as consisting of two factors (e.g., Hare, 2003; Harpur, Hakstian, \& Hare, 1988). Factor 1 measures interpersonal/affective components associated with psychopathy. Factor 2 measures behavioral components of psychopathy (Hare, 1991, 2003). Cronbach's alpha coefficients range from .85 to .87 (Hare, 1991, 2003). 
Psychopathic Personality Inventory (PPI; Lilienfeld \& Andrews, 1996). This 187-item instrument was designed to measure psychopathic personality traits in non-forensic populations. The PPI consists of eight subscales: Machiavellian Egocentricity (ME); Social Potency (SP); Coldheartedness (CH); Carefree Nonplanfulness (CN); Fearlessness (F); Blame Externalization (BE); Impulsive Nonconformity (IN); and Stress Immunity (SI). Participants rate each PPI item along a four-point Likert scale ( 1 = false, 4 = true). Lilienfeld and Andrews reported that one month test-retest reliability for the PPI was .95. Reports of the PPI's internal consistency range from .90 to .93 for the total score and from .70 to .89 for subscales (Lilienfeld \& Andrews, 1996; Poythress et al., 1998).

\subsection{Procedure}

Advanced graduate students enrolled in a clinical psychology doctoral program and completing externships in the forensic unit of a state psychiatric hospital recruited participants. Graduate students informed participants about the purpose of the study, emphasized the voluntary and confidential nature of participation, and encouraged participants to ask questions as needed. After obtaining the participant's verbal informed consent, the research protocol was administered individually, as close to the time of the participant's admission as possible, typically within the first few weeks after admission. Participants marked their responses on their packet and returned the packet to the graduate student after completion. Refusal rates were less than five percent. Graduate students coded the PCL-R based primarily on file review, though in some cases, participants were interviewed, if required for clinical purposes. All raters who took part in the study were trained to score the instrument using case materials from the facility. Each rater completed a minimum of five practice protocols, and discussed inconsistencies with the trainer, prior to beginning coding for the development study. This training protocol is consistent with the recommendations provided in the PCL-R manual: "Training within an institution should be conducted by an individual who is experienced in the administration, scoring and interpretation of the PCL-R. We recommend that clinicians complete five to ten practice assessments and achieve acceptable levels of interrater reliability," (Hare, 1991, p. 5). Raters coded 21 of the same files to establish interrater reliability (ICC $=.83)$. Demographic information was also 
collected via file review. Recidivism data was obtained from a state-wide criminal justice database that included subsequent arrests, charges, and convictions following the participant's release date from an institutional setting. Unless otherwise specified (e.g., sexual recidivism, non-sexual violent recidivism), this study operationalized recidivism as any new charge or conviction.

\section{Results}

Several sets of analyses were conducted to assess the first two hypotheses. To test the first hypothesis, a Pearson correlation analysis was conducted using the total scores of the PPI and the PCL-R, Factor 1 and Factor 2 of the PCL-R, and the subscales of the PPI. Significant correlations were revealed between the Coldheartedness scale of the PPI and the PCL-R total score and Factor 1 score (see Table 3 ). To test the second hypothesis, attempting to replicate the model proposed by Benning et al. (2003), a Confirmatory Factor Analysis (CFA) was conducted using M-Plus. The maximum likelihood estimation model was utilized to the estimates of factor loading. Fit indices for the model proposed

Table 3 Pearson correlations between PPI and PCL-R $(n=143)$.

\begin{tabular}{|c|c|c|c|c|c|c|c|c|c|c|c|c|c|c|}
\hline & 1 & 2 & 3 & 4 & 5 & 6 & 7 & 8 & 9 & 10 & 11 & 12 & 13 & 14 \\
\hline 1. PPI tot & - & .22 & $.79^{*}$ & .30 & $.68^{*}$ & $.21^{*}$ & $.65^{\star \star}$ & $.43^{\star *}$ & $.51^{\star \star}$ & -.08 & .12 & .19 & $.50^{* *}$ & $.81^{* *}$ \\
\hline 2. PCL-R tot & & - & .04 & .13 & .15 & $.28^{*}$ & .09 & .13 & -.04 & .13 & $.88^{* *}$ & $.90^{\star \star}$ & .19 & .08 \\
\hline 3. ME & & & - & -.03 & $.41^{\prime}$ & .01 & $.52^{\star \star}$ & $.39^{\star \star}$ & $.51^{\star \star}$ & $-.38^{\star \star}$ & .01 & .01 & .08 & $.87^{\star \star}$ \\
\hline 4. SP & & & & - & .22 & .03 & .04 & $-.21^{*}$ & $-.29^{\star \star}$ & $.47^{\star \star}$ & .06 & .10 & $.83^{* *}$ & -.15 \\
\hline 5. F & & & & & - & -.05 & $.47^{\star *}$ & $.19^{*}$ & .16 & .03 & .03 & .16 & $.65^{* *}$ & $.42^{\star \star}$ \\
\hline 6. $\mathrm{CH}$ & & & & & & - & $-.23^{* *}$ & $-.27^{\star *}$ & $.18^{*}$ & $.29^{* *}$ & $.35^{* *}$ & .17 & .08 & -.09 \\
\hline 7. IN & & & & & & & - & $.44^{* *}$ & $.40^{\star *}$ & $-.31^{* *}$ & .04 & .01 & $.17^{\star}$ & $.74^{* *}$ \\
\hline 8. $\mathrm{BE}$ & & & & & & & & - & $.21^{*}$ & $-.46^{\star \star}$ & -.01 & .21 & -.16 & $.69^{* *}$ \\
\hline 9. $\mathrm{CN}$ & & & & & & & & & - & $-.41^{\star \star}$ & -.09 & .03 & $-.21^{*}$ & $.67^{\star \star}$ \\
\hline 10. SI & & & & & & & & & & - & .16 & .07 & $.59^{* *}$ & $-.52^{\star \star}$ \\
\hline 11. Factor 1 & & & & & & & & & & & - & $.64^{* *}$ & .19 & .08 \\
\hline 12. Factor 2 & & & & & & & & & & & & - & .10 & -.01 \\
\hline 13. PPI-I & & & & & & & & & & & & & - & -.04 \\
\hline 14. PPI-II & & & & & & & & & & & & & & - \\
\hline
\end{tabular}

1 = PPI total; 2 = PCL-R total; 3 = ME (Machiavellian Egocentricity); 4 = SP (Social Potency); 5 = F (Fearlessness); 6 = CH (Coldheartedness); 7 = IN (Impulsive Nonconformity); 8 = BE (Blame Externalization); 9 = CN (Carefree Nonplanfulness); $10=$ SI (Stress Immunity); 11 = Factor 1 (PCL-R, Factor 1); 12 = Factor 2 (PCL-R, Factor 2); 13 = PPI-I (Fearless Dominance, represents factor 1 of the Benning et al., 2003 model); 14 = PPI-II (Impulsive Antisociality) represents factor 2 of the Benning et al., 2003 model).

* Significant at the $\mathrm{p}<.05$ level.

** Significant at the $\mathrm{p}<.01$ level. 
Table 4 Confirmatory factor analysis factor loadings for the proposed two-factor model of the PPI ( $\mathrm{n}=143)$.

Fearless dominance (PPI-I) Impulsive antisociality (PPI-II)

\begin{tabular}{lll}
\hline Impulsive nonconformity (IN) & & $.787 \star$ \\
Carefree nonplanfulness (CN) & & $.63{ }^{\star}$ \\
Machiavellian egocentricity (ME) & & .801 \\
Blame externalization (BE) & & $.606 *$ \\
Social POTENCY (SP) & .127 & \\
Fearlessness (F) & 1.73 & \\
Stress immunity (SI) & .126 & \\
\hline
\end{tabular}

* Significant at the $\mathrm{p}<.05$ level.

by Benning et al. (2003) were poor $\chi^{2}(14)=97.632$, $p<.000$, TLI $=.748$, $\mathrm{CFI}=.622$, RMSEA $=.204$. Table 4 displays the standardized loadings for the CFA model. Due to the poor fit of the CFA model, an Exploratory Factor Analysis (EFA) was conducted to examine a factor structure for the data. The data was analyzed freely, in order to examine the number of factors that emerged to account for as much of the covariance as possible. A principal components analysis with varimax (orthogonal) rotation was used, with the three rotated factors accounting for $72.01 \%$ of the variance (see Table 5). A similar structure to that proposed by Benning et al. (2003) emerged, but the Fearlessness subscale loaded onto a different factor.

Table 5 Factor loading from the exploratory factor analysis of the PPI ( $n=143)$, demonstrating different factor loading than previous factor analyses conducted with similar data.

\begin{tabular}{lccr} 
& Factor 1 & Factor 2 & Factor 3 \\
\hline Impulsive nonconformity & $\mathbf{. 8 0 0}$ & -.080 & -.254 \\
Carefree nonplanfulness & $\mathbf{5 5 3}$ & -.552 & .399 \\
Machiavellian egocentricity & $\mathbf{8 0 2}$ & -.238 & .087 \\
Blame externalization & $\mathbf{4 6 1}$ & -.388 & -.473 \\
Social potency & .164 &. $\mathbf{8 3 3}$ & -.011 \\
Fearlessness &. $\mathbf{7 4 8}$ & .348 & -.051 \\
Stress immunity & -.270 &. $\mathbf{7 7 1}$ & .313 \\
Coldheartedness & -.022 & .048 & $\mathbf{. 9 0 3}$ \\
\hline
\end{tabular}

Bolded entries are the highest loading items. 
Table 6 ROC results of psychopathy measures and recidivism.

\begin{tabular}{lrrr} 
& $\begin{array}{r}\text { Sexual } \\
\text { recidivism }\end{array}$ & $\begin{array}{r}\text { Non-sexual violent } \\
\text { recidivism }\end{array}$ & $\begin{array}{r}\text { Any } \\
\text { recidivism }\end{array}$ \\
\hline PPI total score & .314 & .630 & .505 \\
& $(\mathrm{n}=81)$ & $(\mathrm{n}=81)$ & $(\mathrm{n}=83)$ \\
PPI - I (PPI; fearless dominance) & .493 & .583 & .517 \\
& $(\mathrm{n}=81)$ & $(\mathrm{n}=81)$ & $(\mathrm{n}=83)$ \\
PPI - II (PPI; impulsive antisociality) & .297 & .616 & .512 \\
& $(\mathrm{n}=81)$ & $(\mathrm{n}=81)$ & $(\mathrm{n}=83)$ \\
PCL-R total score & .366 & $.710^{*}$ & .591 \\
& $(\mathrm{n}=70)$ & $(\mathrm{n}=70)$ & $(\mathrm{n}=72)$ \\
PCL-R factor 1 & .537 & .646 & .611 \\
& $(\mathrm{n}=64)$ & $(\mathrm{n}=64)$ & $(\mathrm{n}=66)$ \\
PCL-R factor 2 & .313 & $.753^{* *}$ & .572 \\
& $(\mathrm{n}=64)$ & $(\mathrm{n}=64)$ & $(\mathrm{n}=66)$ \\
\hline
\end{tabular}

${ }^{*} \mathrm{p}<.05$

${ }^{\star *} \mathrm{p}<.01$

Finally, ROC analyses were used to provide standardized comparisons of the accuracy of the PPI and PCL-R scores in predicting recidivism (sexual, violent, and all recidivism; Table 6 displays results from all 18 ROC analyses). ROC analyses were selected as an optimal statistical technique because the outcome variable's base rate does not influence AUC values. AUC values were calculated only for cases that included recidivism data and PPI scores $(n=83)$ or recidivism data and PCL-R scores $(\mathrm{n}=72)$. Of the cases with PPI and recidivism data, 30 individuals (36.1\%) committed acts detected as recidivism, while 53 did not. Of the cases with PCL-R and recidivism data, 22 individuals (30.6\%) committed acts detected as recidivism, while 50 did not. Of note, all cases with PPI scores also included PCL-R scores. Variations in sample size are due to occasional cases with missing data. Few findings were significant, though some non-significant AUC values exceeded a level of prediction that could be accomplished by chance alone (i.e., AUC $=.50$ ), suggesting a lack of statistical power. These relationships may reach significance in a larger sample size that would afford more instances of future violence (Swets, Dawes, \& Monahan, 2000).

Some scholars believe that ROCs yield an acceptable level of discrimination only when the AUC values exceed 0.70 (Hosmer \& Lemeshow, 2000). Other scholars discourage judging results according to absolute 
cut-offs, and instead recommend that researchers and audiences alike interpret AUC values by comparing them to similar results in the relevant field of research (Rice \& Harris, 2005). With the latter approach, an AUC value's clinical significance evolves based on the predictive power of AUCs that address comparable research questions. While two of the ROC analyses yielded AUC values above Hosmer and Lemeshow's recommended cut-off of 0.70 , most AUC values that exceeded chance levels of discrimination hovered between a modest 0.61 and 0.65 .

The current study's PCL-R total score AUC values are similar to those from powerful meta-analyses that have examined the relationship between psychopathy, as measured by PCL-R total score, and recidivism. Singh, Grann, and Fazel (2011) reported a median AUC of 0.66, with an interquartile range of 0.54 to $0.68(n=2,645)$. Likewise, Yang, Wong, and Coid (2010) found a median AUC of $0.65(n=3,854)$. To date, no published peer-reviewed studies have reported relationships between PPI scores and recidivism.

\section{Discussion}

For the most part, results failed to support the research hypotheses. The PPI total score was not positively correlated with the PCL-R total score and the PCL-R factor scores (Hypothesis 1), the two-factor model of psychopathy as measured by the PPI showed a poor fit to the current study's forensic sample (Hypothesis 2), and there was no statistically significant relationship between psychopathy scores and recidivism (Hypothesis 3).

Although the first hypothesis predicted significant relationships between the PPI total score and PCL-R total and factor scores, results did not approach significance. However, correlations using the instruments' scales revealed a significant relationship between the PPI Coldheartedness scale and the PCL-R total scale and Factor 1 scale. While this finding contrasts with previous research that found moderate/modest correlations between the PPI Coldheartedness scale and both PCL-R factors, (Poythress et al., 1998), it makes conceptual sense considering that the PPI Coldheartedness scale taps into callousness, lack of guilt and lack of sentimentality, all of which are personality traits that load onto Factor 1. Interestingly, the PPI Coldheartedness scale does not appear on either 
of the Factors proposed by Benning et al. (2003). Rather, the PPI Coldheartedness scale emerged as a significantly different scale than those comprising the factors in the present study. A potential explanation for this finding may be that, as some authors have argued, personality traits as opposed to behaviors are more critical to the construct of psychopathy. From this perspective, the traits measured by the PPI Coldheartedness scale represent core personality features of psychopathy, providing a tenable justification for why this scale emerged separately from the other two scales (Lynam \& Gudonis, 2005).

The second hypothesis predicted that Benning et al.'s (2003) two-factor model of psychopathy would generalize to a forensic sample. CFA results indicated a poor fit, while EFA results revealed a model with slightly different factor loadings. Namely, the PPI Fearlessness scale, which was proposed to load onto the Fearless Dominance factor, instead loaded onto the Impulsive Antisociality factor. This finding suggests that the two-factor model may not be a good fit, which is similar to the findings of Neumann et al. (2008). Further this finding suggests that the PPI factor structure in our sample may be complex. Of note, the EFA conducted in this study was simply to further examine the data, however the authors recognize that given the limited sample size, it would be difficult to draw conclusions about the specific nature or validity of the factors and therefore, did not interpret these results.

The third hypothesis proposed that individuals scoring high on measures of psychopathy would be more likely to recidivate than those scoring low. Results did not reveal a significant relationship between psychopathy and recidivism. There is a strong likelihood that with a larger sample, the results may have been different; therefore, these results should be interpreted with caution.

The findings of this study suggest that the PPI, which was normed on a non-clinical sample, is likely not an appropriate means to measure psychopathy in a forensic population. The PPI was revised in order to make it more applicable for forensic and clinical populations and one could argue this study supports the revision because many of the results were in expected directions even though they tended to fall short of statistical significance. The findings could also relate to the differences between the PCL-R and PPI along the lines of administration (clinician ratings versus self-report), psychometric properties (correlated versus uncorrelated factors; Patrick, Fowles, \& Krueger, 2009), and that 
the two instruments measure different conceptualizations of psychopathy focusing on personality instead of behavioral aspects. The lack of the relationship between the PCL-R and the PPI, which is a measure of psychopathy based primarily on the personality features, may suggest that the instruments are measuring different aspects of the constructs. Such an explanation could support the call for converging evidence and multiple methods of assessing psychopathy (Lynam et al., 2011; Skeem \& Cooke, 2010).

However, the present results differ from the findings of Kruh et al. (2005), suggesting that in other forensic samples, the PPI shares a relationship with other measures of psychopathy. Kruh et al.'s (2005) reliance on the PCL:SV instead of the PCL-R may account for some of the differences in results because the PCL:SV omits some of the PCL-R's items. That said, the PCL-SV it is generally considered more appropriate for use with less severe populations. Given that the original authors were concerned that the PPI would show limited utility with more pathological and antisocial populations, it again may make sense that different versions of the PCL-R yielded divergent results within otherwise similar forensic samples. Furthermore, the results of the Kruh et al., study are based on a very small sample size, which limits generalizability to other forensic populations.

In turn, limitations of the present study make it difficult to generalize the results, and suggest that they should be interpreted cautiously. There was a lack of diversity in the offenses committed by the sample, resulting in a higher proportion of sexual offenses, suggesting that the results may be more representative of a sex offender population than of a general forensic population. The sample size was relatively small, though larger than past efforts, particularly considering individuals who had the opportunity to recidivate.

\section{Study 2: Exploration of the PPI-R in a forensic sample}

Recently, literature has drawn attention to the heavy reliance by clinicians and researchers rely on the PCL-R to measure psychopathy. For example, Skeem and Cooke (2010) caution against conflating PCL-R with the actual construct of psychopathy. These concerns have sparked the development of instruments that offer novel ways of measuring 
psychopathy (e.g., Lynamet al., 2011). To promote an understanding of psychopathy that is unbiased by a single measurement procedure, it is useful to examine the relationship between proxy variables and multiple measures of psychopathy. Previous research has examined the relationship between criminal thinking and psychopathy and found significant relationships (Gonsalves, Scalora, \& Huss, 2009). In addition, since empathic deficits are a cardinal feature of psychopathy (Cleckley, 1941, 1976), many researchers have examined measures of empathy in relation to psychopathy (Mullins-Nelson, Salekin, \& Leistico, 2006). Finally, sensation-seeking has been examined because of its relationship to impulsive behaviors (Vitacco \& Rogers, 2001). Moreover, the second study used the revised version of the PPI, the PPI-R.

In study two, the PPI and the PPI-R were compared to the PCL-R within a subsample of the same participants that provided data for study one. It was hypothesized that the PPI-R would be positively correlated with constructs associated with psychopathy: criminal thinking, empathic deficits, and sensation-seeking. Additionally, associations between instruments designed to measure the three psychopathy-related constructs, violent history, and future violent behavior were examined.

\section{Method}

\subsection{Participants}

PPI-R data was collected from 95 participants. Of those 95 participants, PPI data was available for 65 of the participants. Descriptive statistics are summarized in Table 6.

\subsection{Measures}

Psychopathic Personality Inventory - Revised (PPI-R; Lilienfeld \& Widows, 2005). The PPI-R is a revised version of the PPI that consists of 154 self-report items. Items are rated in a similar fashion to those on the PPI. The eight content scales are the same, but the PPI-R also yields two factor scores: Self-centered Impulsivity (SCI) and Fearless Dominance (FD). There are three validity scales used to screen for random or otherwise problematic responding: Virtuous Responding, Deviant 
Responding and Inconsistent Responding. The instrument's total score has yielded satisfactory internal consistency $(\alpha>.80)$ in community and college samples. Test-retest stability ranged from $r=.82$ to $r=$ .95 and was evaluated over an average period of 19.94 days. The alpha coefficient for the total score for this sample was .91. Reliability for the SCI factor was .90 and .87 for the FD factor. Alpha coefficients for the scales ranged from .76 (Coldheartedness) to .86 (Fearlessness and Blame Externalization).

Psychological Inventory of Criminal Thinking Styles (PICTS; Walters, 1995,2002 ) is a self-report measure that uses a four-point Likert scale. There are eight scales, each of which represents a different style of criminal thinking: Mollification (MO), Cutoff (CO), Entitlement (EN), Power Orientation (PO), Sentimentality (SN), Superoptimism (SO), Cognitive Indolence (CI), and Discontinuity (DS). The Mollification scale assesses externalization of blame for the negative consequences of a criminal lifestyle. The Cutoff scale assesses a tendency to justify criminal behavior with the use of alcohol, drugs, mental impairment, images or phrases. The Entitlement scale assesses the belief that one can break societal rules for personal gain. The Power Orientation scale assesses the need to achieve a sense of control or authority over others. The Sentimentality scale assesses the belief that one is a good person, and that good deeds can counteract negative ones. The Superoptimism scale assesses the belief that the negative consequences of criminal activity can be avoided indefinitely. The Cognitive Indolence scale assesses critical reasoning and reliance on cognitive short-cuts to solve problems. Finally, the Discontinuity scale assesses inconsistency between thoughts and behaviors (Palmer \& Hollin, 2004; Walters, 2005a). Cronbach's alpha coefficients of internal consistency for each of the eight scales range from .55 to .79 (Walters, 2005a). Recent research suggests the emergence of a two-factor (Proactive and Reactive) model, and a score representing a unitary measure of cognition (GCT; Walters, 2005b, 2008). Because of research suggesting the superiority of the GCT and the Proactive and Reactive scores (Gonsalves et al., 2009; Walters, 2008), these scores were utilized in the analyses for the present study.

Interpersonal Reactivity Index (IRI; Davis, 1980). The IRI is a 28item self-report scale designed to measure empathy. Items are scored on a 5-point Likert scale, ranging from 1 = strongly agree to $5=$ strongly disagree. There are four subscales: Perspective-Taking (PT), Empathic 
Concern (EC), Fantasy (FS) and Personal Distress (PD). The Perspective-Taking scale evaluates an individual's ability to take another's point of view while interacting with other people. The Fantasy scale measures an individual's tendency to transpose oneself into fictional situations. The Empathic Concern scale evaluates the degree to which one feels warmth, compassion and concern for other individuals. Finally, the Personal Distress scale measures one's negative reactions (i.e. feelings of discomfort) in response emotion displayed by others. Alpha coefficients ranged from .71 to .77 for the subscales, and test-retest coefficients ranged from .62 to .71 .

Zuckerman Sensation Seeking Scale (ZSSS; Zuckerman, 1971, 1979; Zuckerman, Kolin, Price, \& Zoob, 1964). The ZSS is a 40-item instrument consisting of four factors: Thrill and Adventure Seeking (TAS); Experience Seeking (ES); Disinhibition (DIS); and Boredom Susceptibility (BS). Each factor contains ten items designed to measure individual differences for optimal levels of arousal and stimulation. For each item, participants select one of two statements that most accurately reflects their typical behavior. Alpha reliability for the subscales range from .75 (ES) to .80 (DIS \& TAS; Roberti, Storch, \& Bravata, 2003).

\subsection{Procedure}

Data was collected from participants as described in Study 1. Participants who had completed the packet at the time of admission were identified and invited to complete a PPI-R.

\section{Results}

To test the relationship between the psychopathy and related constructs, Pearson correlations were conducted between the three psychopathy measures, the IRI, the PICTS and the ZSSS. Correlations between the psychopathy measures are summarized in Table 7. Correlations between the PPI-R and the IRI, PICTS and ZSS are summarized in Table 8. Correlations between the latter measures, the PCL-R, and the PPI are summarized in Tables 9 and 10. 
Table 7 Correlations between measures of psychopathy.

\begin{tabular}{|c|c|c|c|c|c|c|c|c|c|}
\hline & 1. & 2. & 3. & 4. & 5. & 6. & 7. & 8. & 9. \\
\hline \multirow[t]{2}{*}{ 1. PPI-R total score } & - & $.77^{\star \star}$ & $.51^{\star \star}$ & .20 & .13 & .21 & $.76^{\star \star}$ & $.49^{* *}$ & $.57^{\star \star}$ \\
\hline & & $\mathrm{n}=95$ & $\mathrm{n}=95$ & $\mathrm{n}=95$ & $\mathrm{n}=95$ & $\mathrm{n}=95$ & $\mathrm{n}=65$ & $\mathrm{n}=65$ & $\mathrm{n}=65$ \\
\hline \multicolumn{2}{|l|}{ 2. SCI (PPI-R factor) } & - & -.11 & .11 & -.01 & .22 & $.55^{\star \star}$ & .00 & $.71^{\star *}$ \\
\hline \multicolumn{2}{|l|}{ 3. FD (PPI-R factor) } & & - & .18 & $.24^{*}$ & .03 & $.41^{\star \star}$ & $.76^{* *}$ & -.08 \\
\hline \multicolumn{2}{|l|}{ 4. PCL-R total score } & & & - & $.82^{* *}$ & $.84^{\star \star}$ & $.16^{*}$ & $.17^{\star}$ & .05 \\
\hline \multicolumn{2}{|l|}{ 5. PCL-R Factor 1} & & & & - & $.45^{\star \star}$ & .02 & $.17^{\star}$ & -.13 \\
\hline \multicolumn{2}{|l|}{ 6. PCL-R Factor 2} & & & & & - & $.20^{*}$ & .10 & .15 \\
\hline \multicolumn{2}{|c|}{ 7. PPI total score } & & & & & & - & $.53^{* *}$ & $.81^{* *}$ \\
\hline \multicolumn{2}{|c|}{ 8. PPI- I (PPI fearless dominance) } & & & & & & & - & -.00 \\
\hline \multicolumn{2}{|c|}{ 9. PPI-II (PPI, impulsive antisociality) } & & & & & & & & - \\
\hline
\end{tabular}

${ }^{*}$ Significant at the $\mathrm{p}<.05$ level.

${ }^{* *}$ Significant at the $\mathrm{p}<.00$ level.

Table 8 Correlations between the PPI-R and measures of related constructs.

\begin{tabular}{|c|c|c|c|c|c|c|c|c|c|c|c|c|c|c|c|}
\hline & 1. & 2. & 3. & 4. & 5. & 6. & 7. & 8. & 9. & 10. & 11. & 12. & 13. & 14. & 15. \\
\hline 1. PPI-R total score & - & $.77^{\star \star}$ & $.51^{\star *}$ & 0.14 & -.18 & .19 & .10 & $.24^{*}$ & .07 & $.34^{\star *}$ & $.34^{\star \star}$ & $.40^{\star \star}$ & $.25^{\star}$ & $.31^{\star \star}$ & $.36^{* *}$ \\
\hline 2. SCI & & - & -.11 & -.20 & -.18 & .25 & .16 & .02 & .05 & $.33^{\star \star}$ & $.47^{\star \star}$ & $.33^{* k}$ & $.36^{\star \star}$ & $.58^{\star *}$ & $.58^{\star}$ \\
\hline 3. FD & & & - & .06 & .01 & -.00 & -.04 & $.42^{\star \star}$ & .05 & .03 & -.09 & .19 & -.12 & $-.26^{\star}$ & -.22 \\
\hline 4. ZTAS & & & & - & .07 & -.09 & -.05 & -.04 & -.08 & -.07 & -.08 & -.06 & -.07 & -.10 & $-.31^{\star \star}$ \\
\hline 5. ZES & & & & & - & .05 & .02 & -.02 & -.02 & $-.18^{\star}$ & $-.21^{*}$ & -.14 & -.15 & -.16 & $-.26^{\star \star}$ \\
\hline 6. ZDIS & & & & & & - & .04 & .00 & $.23^{* *}$ & .11 & .14 & .15 & $.22^{*}$ & $.21^{*}$ & $.22^{*}$ \\
\hline 7. ZBS & & & & & & & - & .01 & .02 & .08 & $.17^{*}$ & .09 & .06 & $.17^{\star}$ & .12 \\
\hline 8. ZTOT & & & & & & & & - & $.34^{* *}$ & $.27^{\star *}$ & $.15^{*}$ & $.20^{* *}$ & -.02 & -.12 & -.11 \\
\hline 9. IRI PT & & & & & & & & & - & $.26^{* *}$ & $.33^{\star \star}$ & $.70^{\star *}$ & $.19^{*}$ & .11 & .13 \\
\hline 10. IRI EC & & & & & & & & & & - & $.54^{\star \star}$ & $.77^{\star \star}$ & $.44^{* *}$ & $.42^{\star \star}$ & $.48^{* \star}$ \\
\hline 11. IRI FS & & & & & & & & & & & - & $.67^{\star *}$ & $.51^{\star \star}$ & $.40^{\star *}$ & $.52^{* *}$ \\
\hline 12. IRI PD & & & & & & & & & & & & - & $.37^{\star *}$ & $.26^{\star *}$ & $.34^{* *}$ \\
\hline 13. PICTS Proactive & & & & & & & & & & & & & - & $.60^{* *}$ & $.84^{* *}$ \\
\hline 14. PICTS Reactive & & & & & & & & & & & & & & - & $.89^{* *}$ \\
\hline 15. PICTS GCT & & & & & & & & & & & & & & & - \\
\hline
\end{tabular}

${ }^{*}$ Significant at the $\mathrm{p}<.05$ level.

${ }^{* *}$ Significant at the $\mathrm{p}<.00$ level.

Table 9 Correlations between the PCL-R and measures of related constructs.

\begin{tabular}{|c|c|c|c|c|c|c|c|c|c|c|c|c|c|c|c|}
\hline & 1. & 2. & 3. & 4. & 5. & 6. & 7. & 8. & 9. & 10. & 11. & 12. & 13. & 14. & 15. \\
\hline 1. PCL-R total score & - & $.82^{\star *}$ & $.84^{\star *}$ & .14 & .05 & .05 & .12 & .13 & $.18^{*}$ & .07 & .04 & -.02 & .12 & .03 & .01 \\
\hline 2. PCL-R Factor 1 & & - & $.45^{\star *}$ & .14 & .00 & -.07 & .01 & .04 & .08 & .05 & -.07 & -.07 & .08 & -.13 & -.08 \\
\hline 3. PCL-R Factor 2 & & & - & .06 & .06 & $.26^{*}$ & $.18^{*}$ & $.22^{* *}$ & .08 & .00 & -.11 & .04 & .11 & .13 & .08 \\
\hline 4. ZTAS & & & & - & $.34^{* *}$ & $.27^{\star *}$ & $.15^{\star}$ & $.70^{* *}$ & -.04 & -.02 & .00 & .01 & -.02 & -.12 & -.11 \\
\hline 5. ZES & & & & & - & $.46^{* *}$ & $.33^{\star \star}$ & $.70^{\star *}$ & -.08 & -.02 & $.23^{\star \star}$ & .02 & $.19^{\star}$ & .11 & .13 \\
\hline 6. ZDIS & & & & & & - & $.54^{* *}$ & $.77^{\star *}$ & -.07 & $-.18^{*}$ & .11 & .08 & $.44^{* *}$ & $.42^{* \star}$ & $.48^{\star \star}$ \\
\hline 7. ZBS & & & & & & & - & $.67^{\star \star}$ & -.08 & $-.21^{*}$ & .14 & $.17^{*}$ & $.51^{\star *}$ & $.40^{* *}$ & $.52^{* \star}$ \\
\hline 8. ZTOT & & & & & & & & - & -.06 & -.14 & .14 & .09 & $.37^{\star \star}$ & $.26^{* *}$ & $.34^{* *}$ \\
\hline 9. IRI PT & & & & & & & & & - & .07 & -.09 & -.05 & -.07 & -.10 & $-.31^{\text {*t }}$ \\
\hline 10. IRI EC & & & & & & & & & & - & .05 & .02 & -.15 & -.16 & $-.26^{* \star}$ \\
\hline 11. IRI FS & & & & & & & & & & & - & .04 & $.22^{\star}$ & $.21^{*}$ & $.22^{\star \star}$ \\
\hline 12. IRI PD & & & & & & & & & & & & - & .06 & $.17^{\star}$ & .12 \\
\hline 13. PICTS Proactive & & & & & & & & & & & & & - & $.60^{\star *}$ & $.84^{* \star}$ \\
\hline 14. PICTS Reactive & & & & & & & & & & & & & & - & $.89^{* \star}$ \\
\hline 15. PICTS GCT & & & & & & & & & & & & & & & - \\
\hline
\end{tabular}

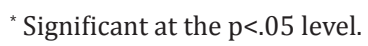

${ }^{* *}$ Significant at the $\mathrm{p}<.00$ level. 
Table 10 Correlations between the PPI and measures of related constructs.

\begin{tabular}{|c|c|c|c|c|c|c|c|c|c|c|c|c|c|c|c|}
\hline & 1. & 2. & 3. & 4. & 5. & 6. & 7. & 8. & 9. & 10. & 11. & 12. & 13. & 14. & 15. \\
\hline 1. PPI total score & - & $.53^{\star \star}$ & $.81^{* \star}$ & $.26^{\star *}$ & $.31^{*}$ & $.63^{* \star}$ & $.55^{\star \star}$ & $.60^{\star \star}$ & -.13 & $-.21^{*}$ & $.20^{*}$ & .00 & $.48^{*}$ & $.38^{\star \star}$ & $.50^{\star *}$ \\
\hline 2. PPI-I & & - & .00 & $.54^{\star *}$ & $.22^{\star \star}$ & $.29^{\star \star}$ & .14 & $.45^{\star \star}$ & -.02 & -.13 & .07 & -.01 & .03 & $-.29^{\star *}$ & -.15 \\
\hline 3. PPI-II & & & - & -.03 & $.25^{\star *}$ & $.55^{* \star}$ & $.56^{* *}$ & $.44^{\star \star}$ & -.14 & -.10 & $.23^{\star \star}$ & .2 & $.54^{\star *}$ & $.68^{\star}$ & $.72^{\star \star}$ \\
\hline 4. ZTAS & & & & - & $.34^{* *}$ & $.27^{\star \star}$ & $.15^{*}$ & $.71^{\star \star}$ & -.04 & -.02 & .00 & .01 & -.02 & -.12 & .11 \\
\hline 5. ZES & & & & & - & $.46^{* \star}$ & $.33^{* *}$ & $.70^{\star \star}$ & -.08 & -.02 & $.23^{\star *}$ & .02 & $.19^{*}$ & .11 & .13 \\
\hline 6. ZDIS & & & & & & - & $.54^{\star \star x}$ & $.77^{\star \star}$ & -.07 & $-.18^{*}$ & .11 & .08 & $.44^{\star \star}$ & $.42^{\star \star}$ & $.48^{\star *}$ \\
\hline 7. ZBS & & & & & & & - & $.67^{\star \star}$ & -.08 & $-.21^{*}$ & .14 & $.17^{*}$ & $.51^{\star \star}$ & $.40^{\star *}$ & $.52^{\star \star}$ \\
\hline 8. ZTOT & & & & & & & & - & -.06 & -.14 & .15 & .09 & $.37^{\star \star}$ & $.26^{\star *}$ & $.34^{\star \star}$ \\
\hline IRI PT & & & & & & & & & - & .07 & -.09 & -.05 & -.07 & -.01 & $-.31^{* *}$ \\
\hline 10. IRI EC & & & & & & & & & & - & .05 & .02 & -.15 & -.16 & $-.26^{\star *}$ \\
\hline 11. IRI FS & & & & & & & & & & & - & .04 & $.22^{\star}$ & $.21^{\star}$ & $.22^{*}$ \\
\hline 12. IRI PD & & & & & & & & & & & & - & .06 & $.17^{\star}$ & .12 \\
\hline 13. PICTS Proactive & & & & & & & & & & & & & - & $.60^{\star *}$ & $.84^{* *}$ \\
\hline 14. PICTS Reactive & & & & & & & & & & & & & & - & $.89^{* *}$ \\
\hline 15. PICTS GCT & & & & & & & & & & & & & & & - \\
\hline
\end{tabular}

${ }^{*}$ Significant at the $\mathrm{p}<.05$ level.

${ }^{* *}$ Significant at the $\mathrm{p}<.00$ level.

Several binary logistic regressions were conducted to examine the relationship between the psychopathy measures and a history of violence. For the first regression, the PCL-R was entered first, followed by the PPI factors. With regard to the psychopathy measures, the PCL-R total score did not indicate a significant first step, $\chi^{2}=.57, d f=1$, Nagelkerke's $\mathrm{R}^{2}$ $=.01, p=.45$. Step two, which included predictors from the first model along with the PPI factors proposed by Benning et al. (2003; PPI-I or Fearless Dominance and PPI-II or Impulsive Antisociality), did not yield a significant result $\left(\chi^{2}=2.06, d f=3\right.$, Nagelkerke's $\left.\mathrm{R}^{2}=.02, p=.56\right)$. For the second regression, the PCL-R was still entered on the first step, and the PPI-R factors, Self-Centered Impulsivity (SCI) and Fearless Dominance (FD), were entered in the second step, revealing significant results $\left(\chi^{2}\right.$ $=7.80 \mathrm{~d} f=3$, Nagelkerke's $\mathrm{R}^{2}=.12, p=.05$ ). Only PPI-R SCI contributed significantly to the model, $\beta=-.03, p=.01$ (see Table 11).

This pattern of data entry was followed with the PCL-R on the first step and the PPI or factors on the second step, for three additional regression analyses with the outcome variables of general, sexual and violent recidivism. There were not enough cases in which an individual had recidivated to examine the PPI-R in relation to recidivism. Results indicated that the PCL-R total score did not significantly predict all types of recidivism, $\chi^{2}=2.90 d f=1$, Nagelkerke's $\mathrm{R}^{2}=.04, p=.09$. After the PPI factors (PPI-I, Fearless Dominance and PPI-II Impulsive Antisociality) were added in step 2 , the model remained non-significant, $\chi^{2}=3.34$ 
Table 11 Results of two regression analyses.

\begin{tabular}{|c|c|c|c|c|c|c|c|c|}
\hline & \multicolumn{2}{|c|}{$\begin{array}{c}\text { History of } \\
\text { violence }\end{array}$} & \multicolumn{2}{|c|}{$\begin{array}{l}\text { General } \\
\text { recidivism }\end{array}$} & \multicolumn{2}{|c|}{$\begin{array}{c}\text { Sexual } \\
\text { recidivism }\end{array}$} & \multicolumn{2}{|c|}{$\begin{array}{l}\text { Violent } \\
\text { recidivism }\end{array}$} \\
\hline & $B$ & $p$ & $B$ & $p$ & $\beta$ & $p$ & $\beta$ & $p$ \\
\hline \multicolumn{9}{|c|}{ Regressions Step 1} \\
\hline PCL-R & .02 & .45 & .06 & .09 & -.04 & .49 & .12 & $.01^{*}$ \\
\hline \multicolumn{9}{|c|}{ PPI Regression Step 2} \\
\hline PPI-II & .01 & .27 & .00 & .71 & -.02 & .09 & .02 & .06 \\
\hline \multicolumn{9}{|c|}{ PPI-R Step 2} \\
\hline PPI-R SCI & -.03 & $.01^{*}$ & - & - & - & - & - & - \\
\hline PPI-R FD & -.00 & .91 & - & - & - & - & - & - \\
\hline
\end{tabular}

* Significant at the $\mathrm{p}<.05$. Note: For all analyses, the PCL-R was added on the first step. Analyses presented in the table represent the second step, but data from the first step are available in the text. There were not enough cases with recidivism and PPI-R data to perform these analyses.

$d f=3$, Nagelkerke's $\mathrm{R}^{2}=.05, p=.34$. The same set of analyses was conducted to explore sexual recidivism only. For the first step, the PCL-R total was not significantly related to sexual recidivism, $\chi^{2}=.49, d f=1$, Nagelkerke's $\mathrm{R}^{2}=.01, p=.48$. Upon adding the PPI factors in the second step, the model was still not significant, $\chi^{2}=4.63, d f=3$, Nagelkerke's $\mathrm{R}^{2}=.10, p=.20$. Finally, analyses were conducted to examine violent recidivism as the outcome variable. In this case, the PCL-R total score did significantly predict violent recidivism, $\chi^{2}=7.102, d f=1$, Nagelkerke's $\mathrm{R}^{2}=.13, p=.01, \beta=.12, p=.01$. After adding the PPI factors in the second step, the model remained significant, $\chi^{2}=10.77, d f=3$, Nagelkerke's $\mathrm{R}^{2}=.19, p=.01$. However, despite the slight improvement in amount of variance accounted for, only the PCL-R contributed significantly to the model, $\beta=.13, p=.01$.

\section{Discussion}

In Study 2, it was hypothesized that psychopathy measures would share positive relationships with measures of criminal thinking, empathic deficits, sensation-seeking (Hypothesis 1), as well as violent history and future violent behavior (Hypothesis 2). The remainder of this section summarizes the partial support for both hypothesis, and explores potential explanations for these findings. 
There were few significant correlations between the PPI, PPI-R and the PCL-R. The PPI and the PCL-R total scores were correlated, as were the PPI-I and PCL-R total score and PCL-R Factor 1 score. With regards to the PPI-R, the only significant relationship was between the Fearless Dominance (FD) factor and PCL-R Factor 1. Given that the PPI and PPI$\mathrm{R}$ measure psychopathy in terms of personality traits rather than behavioral indicators, the lack of correlations between PCL-R Factor 2, and the PPI and PPI-R factors and total scores is not particularly surprising. The instruments' differing conceptualizations of psychopathy could also account for the non-significant relationship between the PPI-R total score and the PCL-R total score. However, it remains uncertain why there was no statistical overlap between Factor 1 of the PCL-R and the PPI-R, given that both scales ostensibly measure personality features associated with psychopathy. Some have argued that the construct of psychopathy has become muddled with the development of the PCL-R (Skeem \& Cooke, 2010). The present results may support this theory and imply that different core elements of the construct are measured by different assessment instrument.

An alternative explanation for this surprising finding is that the PPI$\mathrm{R}$ did not assess psychopathy in a suitable manner for study two's sample. Recall that study one failed to confirm the PPI's factor structure and revealed weak correspondence between PPI factors and PCL-R factors, indicating that the PPI may lack utility for assessing psychopathy in forensic populations (Kruh et al., 2005). By extension, the PPI-R, like its predecessor, may also be better equipped for measuring psychopathy in non-forensic populations. Despite the revision, the current results question the use of the PPI and PPI-R in forensic samples.

A second, related explanation pertains to the level of psychopathy in current study, a consideration that is inseparable from the assessment of psychopathy. As mentioned earlier, the current study's PCL-R scores were determined via file review, whereas PPI and PPI-R scores derived from participants' self-report. Hare and Neumann et al. (2007) discourage reliance on file review to score the PCL-R. They contend that files typically contain insufficient information to accurately score Factor 1 items, which often yields suppressed scores. Instead, they recommend scoring the PCL-R using data obtained from both a file review and an interview with the subject. In the present study, PCL-R coders rarely came across clinical records that directly characterized participants' 
personality traits; rather, they often had to intuit this information from documented behavioral observations. Although personality traits and behaviors clearly influence one another, the likelihood that the present study's PCL-R Factor 1 scores reflect behavioral elements more so than personality traits may explain why these scores failed to share a relationship with the PPI-R.

However, the results clearly suggested converging validity for the selfreport measures of psychopathy in comparison to the individual measures of related constructs. There was significant statistical overlap between all the measures and nearly all the subscales of those measures and the self-report measures of psychopathy. For example, the PPI-R demonstrated a strong relationship with sensation seeking as measured by the Sensation Seeking Scale, particularly in terms of correlations between this instrument's subscales and the Fearless Dominance factor. In addition, the PPI-R total score and factor scores all demonstrated some relationship to criminal thinking as measured by the PICTS, which is consistent with previous research that has suggested the importance of utilizing criminal thinking when considering risk prediction (Gonsalves et al., 2009). Though correlations with empathy as measured by the IRI tended to range from low to nonsignificant, some significance was shown, especially with respect to self-centered impulsivity. These results suggest that the PPI-R correlates with constructs associated with psychopathy in a forensic sample.

Additionally, the PPI demonstrated significance with several measures that are associated with psychopathy. The total score was correlated with just about every measure's total score and factor scores, with the exception of two of the factors on the empathy scale. Benning et al.'s (2003) factors also demonstrated significance. PPI-I was significantly correlated with measures of sensation-seeking and criminal thinking. PPI-II was significantly correlated with measures of sensation-seeking, criminal thinking, and one of the empathy measure's subscales.

These results stand in marked contrast to the PCL-R correlations with the individual measures. Only one subscale of the empathy measure correlated with the PCL-R total and only two subscales of the Zuckerman along with the Zuckerman total correlated with Factor 2. None of the measures correlated with Factor 1 of the PCL-R. In addition, previous research has demonstrated that including a measure of criminal thinking can increase the predictive validity of the PCL-R score, suggesting 
there are other cognitive factors that may influence criminal behavior (Gonsalves et al., 2009). These results clearly highlight a difference between the two self-report measures of psychopathy and the PCL-R in a forensic sample.

PCL-R results from the present two studies disagree with findings from comparable investigations (Gonsalves et al., 2009; Kruh et al., 2005). The divergent outcomes are especially remarkable considering that Gonsalves et al. (2009) research relied on a portion of the very same sample utilized by the present two studies. One reason for the inconsistency may be that the sample Gonsalves et al. relied on exhibited more pronounced psychopathic traits than individuals whose data was added to the sample in preparation for the current two studies. If so, then the data added between Gonsalves et al. and the current two studies may have depressed the mean PCL-R scores for the sample as a whole. A second consideration is that forensic samples tend to display fewer characteristics associated with psychopathy than correctional samples (Hare, 1991, 2003).

Since study two relied on a subset of study one's participants, the two studies suffer from similar limitations. Compared to study one, study two may be even more skewed towards a sex offender sample. By the time researchers administered the PPI-R to participants who had completed the PPI, many of the forensic patients had been discharged; however, most of the sex offenders remained hospitalized and therefore were able to participate. Additionally, a small sample size weakened the second study's results.

\section{Conclusion}

Results from these two studies support the notion that diverse measurement techniques paint different pictures of psychopathy, and raise questions about whether certain instruments and particular methods of administration and scoring may be better suited to particular populations. Ultimately, the lack of significant overlap between the psychopathy measures in the current studies may be best explained by the use of PCL-Rs scored on the basis of file review and lack of the combined interview information. This may provide the best explanation for the lack of significant findings in regard to these measures in the absence of additional 
data criticizing the specific measures used. However, research continues to rely on file review-based PCL-Rs (Mokros et al., 2010) even as others are increasingly questioning the reliance, even for research purposes, on information based solely on file reviews (Laurell \& Daderman, 2007).

Presently, efforts to understand psychopathy are stymied by disagreements over the instrument that measures the construct most accurately. This contention is analogous to the classic tale of blind men attempting to describe an elephant. Each man proffers a different description of the elephant's true nature, depending on the part of the elephant they touched. Likewise, allegiance to a single means of measurement impedes the field's progress towards reconciling the debate over psychopathy-asmeasured and psychopathy-as-construct. Just as it takes many hands to grasp an entire elephant, multiple studies using multiple instruments are essential to develop a procedure for adequately representing the construct of psychopathy. The present study is an early step towards quantifying the impact of different instruments measure psychopathy differently. Future research can continue this line of inquiry by comparing extant instruments, identifying their strengths and limitations, and using this information to development new measurement techniques. As the disconnect between measurement and construct gradually diminishes, the field's understanding of psychopathy will advance.

\section{References}

Benning, S. D., Patrick, C. J., Hicks, B. M., Blonigen, D. M., \& Krueger, R. F. (2003). Factor structure of the Psychopathic Personality Inventory: Validity and implications for clinical assessment. Psychological Assessment, 15, 340-350.

Cleckley, H. (1941). The mask of sanity. St. Louis, MO: C.V. Mosby.

Cleckley, H. (1976). The mask of sanity (5th ed.). St. Louis, MO: C.V. Mosby.

Davis, M. H. (1980). A multidimensional approach to individual differences in empathy. JSAS Catalog of Selected Documents in Psychology, 10, 85.

Edens, J. F., Poythress, N. G., \& Lilienfeld, S. O. (1999). Identifying inmates at risk for disciplinary infractions: A comparison of two measures of psychopathy. Behavioral Sciences and the Law, 17, 435-443.

Edens, J. F., Poythress, N. G., \& Watkins, M. M. (2001). Further validation of the Psychopathic Personality Inventory among offenders: Personality and behavioral correlates. Journal of Personality Disorder, 15, 403-415.

Gonsalves, V. M., Scalora, M. J., \& Huss, M. T. (2009). Prediction of recidivism using the Psychopathy Checklist-Revised and the Psychological Inventory of Criminal Thinking Styles within a forensic sample. Criminal Justice and Behaviors, 36, 741-756. 
Hare, R. D. (1991). The Hare Psychopathy Checklist - revised. Toronto: Multi-Health Systems.

Hare, R. D. (2003). The Hare Psychopathy Checklist - revised. Toronto: Multi-Health Systems.

J., Hakstian, A. R., \& Hare, R. D. (1988). Factor structure of the Psychopathy Checklist. Journal of Consulting and Clinical Psychology, 56, 741-747.

Hart, S. D., Cox, D. N., \& Hare, R. D. (1995). Manual for the psychopathy checklist: screening version (PCL:SV). Toronto: Multi-Health Systems.

Hosmer, D. W., \& Lemeshow, S. (2000). Applied logistic regression (2nd ed.). New York: Wiley.

Huss, M. T., \& Langhinrichsen-Rohling, J. (2006). Assessing the generalization of psychopathy in a clinical sample of domestic violence perpetrators. Law and Human Behavior, 30, 571-586.

Kruh, I. P., Whittemore, K., Arnaut, G. L., Manley, J., Gage, B., \& Gagliardi, G. J. (2005). The concurrent validity of the Psychopathic Personality Inventory and its relative association with past violence in a sample of insanity acquittees. The International Journal of Forensic Mental Health, 4, 135-145.

Laurell, J., \& Daderman, A. M. (2007). Psychopathy (PCL-R) in a forensic psychiatric sample of homicide offenders: Some reliability issues. International Journal of Law and Psychiatry, 30, 127-135.

Lilienfeld, S. O., \& Andrews, B. P. (1996). Development and preliminary validation of self-report measure of psychopathic personality traits in noncriminal populations. Journal of Personality Assessment, 66, 488-524.

Lilienfeld, S. O., \&Widows, M. (2005). Professional Manual for the Psychopathic Personality Inventory-Revised (PPI-R). Lutz, Florida: Psychological Assessment Resources.

Lynam, D. R., Gaughan, E. T., Miller, J. D., Miller, D. J., Mullins-Sweatt, S., \& Widiger, T. A. (2011). Assessing the basic traits associated with psychopathy: Development and validation of the elemental psychopathy assessment. Psychological Assessment, 23, 108-124.

Lynam, D. R., \& Gudonis, L. (2005). The development of psychopathy. Annual Review of Clinical Psychology, 1, 381-407.

Mokros, A., Neuman, C. S., Stadland, C., Osterheider, M., Nedopil, N., \& Hare, R. D. (2010). Assessing measurement invariance of PCL-R assessments from file reviews of North American and German offenders. International Journal of Law and Psychiatry, 34, 56-63.

Mullins-Nelson, J. L., Salekin, R. T., \& Leistico, A. -M. R. (2006). Psychopathy, empathy and perspective-taking ability in a community sample: Implications for the successful psychopathy concept. The International Journal of Forensic Mental Health, 5, 133-149.

Neumann, C. S., Hare, R. D., \& Newman, J. P. (2007). The super-ordinate nature of the Psychopathy Checklist-Revised. Journal of Personality Disorders, 21, 102-117.

Neumann, C. S., Malterer, M. B., \& Newman, J. P. (2008). Factor structure of the Psychopathic Personality Inventory (PPI): Findings from a large incarcerated sample. Psychological Assessment, 20, 169-174. 
J., \& Hollin, C. R. (2004). Predicting reconviction using the psychological inventory of criminal thinking styles with English prisoners. Legal and Criminological Psychology, 9, 57-68.

Patrick, C. J., Fowles, D. C., \& Krueger, R. F. (2009). Triarchic conceptualization of psychopathy: Developmental origins of disinhibition, boldness, and meanness. Development and Psychopathology, 21, 913-938.

Poythress, N. G., Edens, J. F., \& Lilienfeld, S. O. (1998). Criterion-related validity of the Psychopathic Personality Inventory in a prison sample. Psychological Assessment, 10, 426-430.

Ray, J. V., Poythress, N. G., Weir, J. M., \& Rickelm, A. (2009). Relationships between psychopathy and impulsivity in the domain of self-reported personality features. Personality and Individual Differences, 46, 83-87.

Rice, M. E., \& Harris, G. T. (2005). Comparing effect sizes in follow-up studies: ROC area, Cohen's d, and r. Law and Human Behavior, 29, 615-620.

Roberti, J. W., Storch, E. A., \& Bravata, E. (2003). Further psychometric support for the Sensation Seeking Scale-Form V. Journal of Personality Assessment, 81, 291-292.

Salekin, R. T., Rogers, R., \& Sewell, K. W. (1996). A review and meta-analysis of the Psychopathy Checklist and Psychopathy Checklist-Revised: Predictive validity of dangerousness. Clinical Psychology: Science and Practice, 3, 203-215.

Singh, J. P., Grann, M., \& Fazel, S. (2011). A comparative study of violence risk assessment tools: A systematic review and metaregression analysis of 68 studies involving 25,980 participants. Clinical Psychology Review, 31, 499-513.

Skeem, J. L., \& Cooke, D. J. (2010). Is criminal behavior a central component of psychopathy? Conceptual directions for resolving the debate. Psychological Assessment, 22, 433-445.

Skeem, J. L., Polaschek, D. L. L., Patrick, C. J., \& Lilienfeld, S. O. (2011). Psychopathic personality: Bridging the gap between scientific evidence and public policy. Psychological Science, 12, 95-162.

Swets, J. A., Dawes, R. M., \& Monahan, J. (2000). Psychological science can improve diagnostic decisions. Psychological Science, 1, 1-26.

Vitacco, M. J., \& Rogers, R. (2001). Predictors of adolescent psychopathy: The role of impulsivity, hyperactivity, and sensation seeking. The Journal of the American Academy of Psychiatry and the Law, 29, 374-382.

Wallace, J. F., Schmitt, W. A., Vitale, J. E., \& Newman, J. P. (2000). Experimental investigations of information-processing deficiencies in psychopaths: Implications for diagnosis and treatment. In C. B. Gacono (Ed.), The clinical and forensic assessment of psychopathy: A practitioner's guide (pp. 87-109). Mahwah, NJ: Lawrence Erlbaum Associates Publishers.

Walters, G. D. (1995). The psychological inventory of criminal thinking styles. Part I. Reliability and preliminary validity. Criminal Justice and Behavior, 22, 307-325.

Walters, G. D. (2002). The psychological inventory of criminal thinking styles (PICTS): A review and meta-analysis. Assessment, 9, 278-291. 
Walters, G. D. (2003). Predicting institutional adjustment and recidivism with the psychopathy checklist factor scores: A meta-analysis. Law and Human Behavior, 27, 541-558.

Walters, G. D. (2005a). Incremental validity of the psychological inventory of criminal thinking styles as a predictor of continuous and dichotomous measures of recidivism. Assessment, 12, 19-27.

Walters, G. D. (2005b). How many factors are there on the PICTS? Criminal Behaviour and Mental Health, 15, 63-70.

Walters, G. D. (2008). Self-report measures of psychopathy, antisocial personality, and criminal lifestyle: Testing and validating a two-dimensional model. Criminal Justice and Behavior, 35, 1459-1483.

Yang, M., Wong, S. C. P., \& Coid, J. (2010). The efficacy of violence prediction: A metaanalytic comparison of nine risk assessment tools. Psychological Bulletin, 136(5), 740-767.

Zuckerman, M. (1971). Dimensions of sensation seeking. Journal of Consulting and Clinical Psychology, 36, 45-52.

Zuckerman, M. (1979). Sensation seeking: Beyond the optimal level of arousal. Hillsdale, NJ: Lawrence Erlbaum.

Zuckerman, M., Kolin, E. A., Price, L., \& Zoob, I. (1964). Development of a sensationseeking scale. Journal of Consulting and Clinical Psychology, 28, 477-482. 